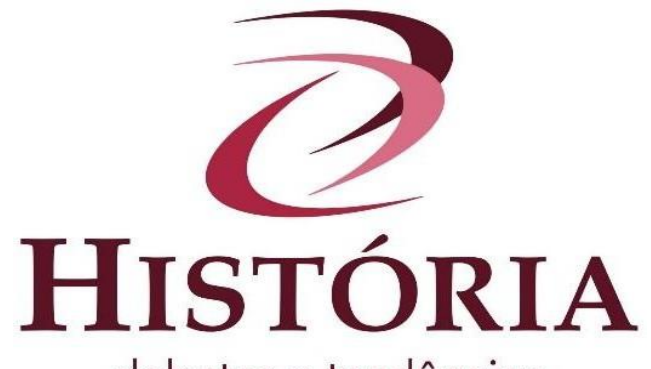

\title{
Doenças, Lutas Sociais, Medicina Tradicional e a Caça às Bruxas
}

\author{
Enfermidades, Luchas Sociales, Medicina Tradicional y Caza a las Brujas
}

\author{
Diseases, Social Struggle, Traditional Medicine and Halloween Hunting
}

\author{
Roseli Tristão Maciel $^{\mathrm{i}}$ \\ Veralúcia Pinheiro ${ }^{\text {ii }}$
}

\begin{abstract}
Todo mundo tem mais espírito que Voltaire, também o povo, que herda e acrescenta a experiência coletiva e milenar, será o maior dos sábios Jean Batiste Vico. (Apud, PEIXOTO, 1977, p.49).
\end{abstract}

Resumo: O objetivo deste estudo é discutir a medicina rústica em relação às lutas sociais ao longo da história noOcidente. Analisa, brevemente, a emergência do capitalismo, da violência das classes privilegiadas e o infortúnio dos trabalhadores expulsos das terras, alvos da Lei dos Pobres e submetidos a uma vida propícia a doenças como a peste negra. $\mathrm{O}$ ápice disso foi o fenômeno da caça às bruxas, que dizimou milhares de mulheres que exerciam a medicina popular no cuidado da saúde dos pobres. Discute as experiências acumuladas pelas mulheres no tratamento das doenças no Brasil, na sua diversidade étnica e cultural formada pelos povos indígenas,afro-descendentes e portugueses e a teia de conhecimentos materializados sob a forma de uma medicina rústica, parte da nossa cultura atual.

Palavras-chave: Bruxas. Medicina Rústica. Mulheres.

Resumen: El objetivo de este estudio es discutir la medicina rústica conrelación a las luchas sociales a lo largo de lahistoriaenelOccidente. Analizalaemergenciadel capitalismo, de laviolencia de lasclasessociales privilegiadas y la desgracia de lostrabajadores expulsados de lastierras, vítimas de laLey de los Pobres submetidos a una vida propicia a enfermedades como la Peste negra. La cumbre de esofueel fenómeno de caza a lasbrujas, que diezmómiles de mujeres que ejercianla medicina popular enel cuidado de lasalud de los pobres. Discute las experiencias acumuladas por lasmujeresenel tratamento de lasenfermedadesen Brasil, ensudiversidad étnica y cultural formada por lospueblos indígenas, afrodescendientes y portugueses y la tela de conocimientos materializados sobre la forma de una medicina rústica, parte de nuestrahistoria cultural.

Palabras-clave: Brujas. Medicina rústica. Mujeres.

\begin{abstract}
The objective of this study is to discuss rustic medicine in relation to social struggles throughout Western history. It briefly analyzes the emergence of capitalism, the violence of the privileged classes, and the misfortune of the workers expelled from the lands, targets of the Law of the Poor and subjected to a life propitious to diseases like the black plague. The apex of this was the phenomenon of witch-hunting, which decimated thousands of women who exercised popular medicine in caring for the health of the poor. He discusses the experiences accumulated by women in the treatment of diseases in Brazil, in its ethnic
\end{abstract}


and cultural diversity formed by indigenous peoples, Afro-descendants and Portuguese, and the web of knowledge materialized in the form of a rustic medicine, part of our current culture.

Keywords: Witches. Rustic medicine. Women.

\section{As doenças e as lutas sociais na Europa feudal}

Se, para Augier (2005), o dinheiroveio ao mundo manchado de sangue numa das faces, para Marx (2013), o capital chegou escorrendo sangue e sujeira por todos os poros, da cabeça aos pés. Para além da violência da expulsão dos camponeses das terras, da aplicação das leis sangrentas conhecidas por Lei dos Pobres, da fome, das longas jornadas de trabalho, que não pouparam nem mesmo as crianças, a história das lutas operárias, especialmente no período de emergência do capitalismo, se caracterizatambém pelas doenças que se transformaram em pandemias,somando-se a tantos outrosinfortúnios dos trabalhadores.

Em sua pesquisa sobre a vida social da mulher na emergência do modo de produção capitalista,Federici (2017, p. 96)registra que a chamada Peste Negra "matou, em média, entre $30 \%$ e $40 \%$ da população europeia", provocando um colapso demográfico sem precedentes. Esta Peste tornou-se ainda mais grave devido ao fenômeno conhecido pela Grande Fome (1315-1322), que já havia debilitado a resistência das pessoas contra as doenças. Para a autora, essas tragédias mudaram profundamente as relações sociais dos europeus daquele período, devido àpostura indiferente dos trabalhadores no que diz respeito às hierarquias sociais. Diante da mortandade generalizada, a disciplina social ficou debilitada, a preocupação com o trabalho e com a obediência às normas sociais e sexuais foi colocada de lado, prevalecendo o desejo de se divertir e festejar, sem preocupação com o futuro.

Uma das melhores descrições da Peste Negra, segundo Resende(2009),encontra-se no Decamerão de Giovanni Bocaccio, que viveu de 1313 a 1375. No prólogo da obra,é possível ter uma ideia do que foi afirmado no parágrafo anterior, a partir de um trecho:

\footnotetext{
A peste, atirada sobre os homens por justa cólera divina e para nossa exemplificação, tivera início nas regiões orientais. Incansável, fora de um lugar para outro, e estendera-se de forma miserável para o ocidente. [...] nenhuma prevenção foi válida, nem valeu a pena qualquer providência dos homens (REZENDE, 2009, p.78).
}

Contudo, do ponto de vista da doença, ou seja, da peste negra,segundo Federici (2017), a consequência fundamental foi o aprofundamento da crise do trabalho, que, ao provocar a dizimação dos trabalhadores, tornou a mão de obra escassa e ao mesmo tempo elevou seu preço, incentivando as pessoas a romperem os laços do domínio feudal. Assim, 
a insuficiência da mão de obra causada pela epidemia modificou as relações de poder em benefício das camadas populares. Segundo a autora, são várias as evidências dessa mudança, dentre elas o aumento das greves de inquilinos, as ameaças de mudança em massa para outras terras ou mesmo para a cidade, a resistência contra o pagamento aos senhores, além do fato de ignorarem suas ordens e os costumes de consertar suas casas, limpar as valas ou capturar os servos fugitivos.

Tal resistência foi exitosa até o final do século XIV, tendo se caracterizado principalmente pelo não isolamento dos trabalhadores. Federici (2017) nos esclarece que aldeias inteiras se organizaram coletivamente para não pagar as multas, os impostos e a talha, negando-se a obedecer às determinações dos tribunais senhoriais, instrumentos fundamentais do poder feudal.

É evidente que a resposta dos senhores feudais reproduziu a violência de costume. De início, buscaram aumentar a exploração do trabalho por meio do restabelecimento da prestação de serviços laborais compulsórios, ou até mesmo da escravidão. Em Florença, por exemplo, em 1366, a importação de escravos foi autorizada, o que fez crescer ainda mais os conflitos envolvendo as classes sociais.

Por outro lado, depois da Peste Negra,os camponeses tiveram mais mobilidade, fugiram da condição de extrema exploração dos senhores feudais na terra e emigram para a cidade. Nas análises deCastel (1999, p. 113), “o século XIV é ainda o momento em que o acesso à mestria se torna cada vez mais difícil e começa a ser reservado aos filhos de mestres". Ora, estes imigrantes rurais, formados por antigos camponeses separados de sua cultura, constituem mão de obra sem qualificação. Por isso, seu crescimento tende a formar uma massa de indivíduos sem recursos que vão caracterizar o novo pauperismo, cujas origens foram as mutações das estruturas agrárias, mas sua manifestação e consolidação acontecem na cidade.

A partir de então, os países europeus procuraram mecanismos para condenar e perseguir a vadiagem, a vagabundagem, a mendicância, enfim, buscaram instrumentos eficazes paraimpor ao indivíduo a obrigação de se submeter a qualquer tipo de trabalho em qualquer condição.Segundo Federici (2017), em sintonia com essas concepções, em 1349, a Inglaterra publicou um Estatuto que condenava os salários altos e a vadiagem, estabelecendo que quem não trabalhasse e não possuísse nenhum meio de sobrevivência teria que aceitar uma ocupação,independente de sua natureza.

Na França, normas semelhantes foram instituídas. Em 1351, as pessoas foram instruídas a não alimentar e tampouco hospedar mendigos e vagabundos saudáveis. Já em 
1354, ficou estabelecido que aqueles que permanecessem ociosos, frequentando tavernas, jogando dados ou mendigando teriam que aceitar algum trabalho ou suportar as duras punições; os infratores primários iam para a prisão a pão e água, enquanto os reincidentes eram colocados no tronco. Quem infringisse a regra pela terceira vez era marcado a fogo na fronte. Na legislação francesa, surgiu um novo elemento que se tornou parte da luta moderna contra os vagabundos: o trabalho forçado. Em Castela, uma norma introduzida em 1387 permitia aos particulares prender vagabundos e forçá-losa trabalhar um mês sem salário.

Essas normas violentas e bárbaras, conforme analisa Kurz (2001), caracterizam os objetivos e o método do capital ainda em seu estado embrionário, procurando crescer e arrancar do trabalhador uma quantidade suficiente de mais-trabalho, por meio dos imperativos econômicos, mas não dispensando a providencial ajuda do poder do Estado. Para o autor, a crueldade destes métodos parece até modesta diante das artimanhas do capital em sua fase adulta, atual.

O capitalismo precisou de vários séculos para impor o que se convencionou chamar de trabalho livre. A própria história do capitalismo nos mostra que foi sob coaçãoque o trabalhador consentiu em vender todo o tempo de sua vidaútil, e até a sua própria capacidade de trabalho, em troca de sua subsistência, ou melhor, por um prato de comida.

\section{A Medicina populare o fenômeno de caça as bruxas}

Em sua pesquisa sobre a mulher, o corpo e a acumulação primitivida, Federici (2007, p. 262)) sustenta a ideia de quea perseguição às bruxas foi o ponto culminante da intervenção estatal contra o corpo proletário na Era Moderna. Para a autora, centenas de milhares de mulheres não poderiam ter sido massacradas e submetidas às torturas mais cruéis se não tivessem desafiado a estrutura de poder. Tamanha guerra contra as mulheres se manteve durante um período de pelo menos dois séculos, marcando um ponto decisivo na história da Europa, numa espécie de pecado original no processo de degradação que as mulheres sofreram com a chegada do capitalismo.

No âmbito da teoria crítica, são poucos os estudos sobre a história da caça às bruxas. Por isso,Federici (2007)questiona as razões que subjazem ao desinteresse dos estudiosos, enfatizando que, ao relegarem a caça às bruxas ao esquecimento, os pesquisadores desse período agem como se tal fato carecesse de relevância para a história da luta de classes.

Contudo, deveria parecer significativo o fato de a caça às bruxas ter sido contemporânea ao processo de colonização e extermínio das populações nativas do Novo 
Mundo, aos cercamentos ingleses, ao começo do tráfico de escravos e à promulgação das Leis Sangrentas contra vagabundos e mendigos, e de ter chegado a seu ponto culminante no interregno entre o fim do feudalismo e a emergência do capitalismo, quando os camponeses na Europa alcançaram o ponto máximo de autonomia, ao mesmo tempo em que sofreram a maior derrota da sua história.

A partir de meados do século XVI, nas mesmas décadas em que os conquistadores espanhóis subjugaram as populações americanas, começou a crescer a quantidade de mulheres julgadas como bruxas. A pesquisa de Federici (2007, p. 297) nos mostra, ainda, que nessa mesma época, a iniciativa da perseguição às mulheres consideradas bruxas passou da inquisição às cortes seculares, alcançando seu ápice entre 1580 e 1630, “numa época em que as relações feudais já estavam dando lugar às instituições econômicas e políticas típicas do capitalismo mercantil".

Na introdução da clássica obra $O$ martelo das feiticeiras (KRAMER; SPENGER, 2015), a pesquisadora Rose Marie Muraro (2015) lembra que, na alta Idade Média, a condição das mulheres havia se tornado próspera. Elas passaram a ter acesso às artes, às ciências e à literatura. Exemplo disso é a monjaHrosvitha de Gandersheim, que foi a única poetisa da Europa ao longo de cinco séculos. Isso aconteceu durante as Cruzadas, período em que não só a Igreja alcança seu maior poder temporal, como também o mundo se prepara para as grandes transformações que viriam séculos mais tarde, com a Renascença.

Em seguida a essa época, no período que compreende o fim do século XIV até meados do século XVIII, é desencadeada a repressão sistemática, ao que Muraro (2015) chamou de repressão do feminino. Trata-se de séculos de caça às bruxas. Segundo a autora, a Inquisição permaneceu durante cerca de quatro séculos, sendo que, do fim do século XV ao começo do século XVI, houveram milhares e milhares de execuções - elas eram queimadas vivas na fogueira - na Alemanha, na Itália e em outros países. Tamanho terror se espalhou por toda a Europa a partir de meados do século XVI, começando pela França e pela Inglaterra, e os pesquisadores estimam que $85 \%$ das execuções eram de mulheres.

As razões que levaram ao massacre dessas mulheres são questionadas por Muraro(2015), encontrando então,num passado distante, a ligação das mulheres com a arte da cura, em outras palavras, com a medicina popular. Para a autora, desde a antiguidade, as mulheres eram as parteiras, as curadoras e detinham saber próprio, que lhes era transmitido de geração em geração. Em muitas sociedades primitivas, eram elas as xamãs. Na Idade Média, a única alternativa para que as mulheres camponesas e pobres pudessem cuidar de sua saúde era recorrer a outras mulheres que se encontravam nas mesmas condições que 
elas.

O papel das mulheres no tratamento dos doentes foi observado também por Alain Corbin, que mostrou que, mesmo no final da Idade Média, as mulheres é que gerenciavam a saúde através de uma complexa rede medicinal, de conhecimento de fitoterápicos que formavam uma verdadeira farmácia, obviamente muito simples, mas que funcionava muito nos castelos, para a aristocracia e para a cura dos pobres. (CORBIN, 1991).

Ocorre, portanto, um aprofundamento desse conhecimento forjado no cotidiano, diante da emergência de um parto, das dores decorrentes das doenças venéreas, da desinteria e febre das crianças etc.

Ao mesmo tempo que o exercício da medicina tradicionalse constitui como uma função quase exclusiva das mulheres camponesas no medievo, ele se torna um dos principais argumentos dos inquisidores para comprovar a prática de bruxaria. $\mathrm{O}$ empirismo que lhes possibilitou conhecimentos relacionados ao tratamento de doenças, identificação de ervas com potencialidades curativas, habilidades para lidar com questões relacionadas à gravidez, parto, sexualidade, contracepção, até mesmo, com o processo da morte e do luto, fora convertido em capacidade de burlar as leis da natureza, interferir no mundo dos mortos e alterar o destino dos vivos.

\section{As mulheres e suas experiências com o tratamento das doenças no Brasil}

Os povos de todas as épocas, dos mais diferentes espaços e culturas, têm em comum o impulso de resolver os obstáculos que a natureza lhes impõe, recorrendo, quando possível, às possibilidades oferecidas pelo mundo físico e, quando não, à soluções de cunho psíquico e/ou espiritual. Portanto, o uso de plantas, animais e minerais, tanto quanto de orações e de rituais, é parte da história da medicina tradicional, e ainda integra, como métodode busca de cura para os males do corpo e da alma de pessoas pertencentes às diferentes classes sociais.

A Medicina Tradicional, conforme conceito desenvolvido por Wong (2008), é a soma total do conhecimento, habilidades e práticas com base nas teorias, credos e experiências de diferentes culturas, sendo explicáveis ou não, usados na manutenção da saúde, bem como em sua prevenção, diagnóstico, melhora ou tratamento de doenças mentais ou físicas.Trata-se de conhecimentos sobre o manuseio e as propriedades curativas de plantas medicinais, de substâncias derivadas de animais ou minerais, bem como, de crenças populares e seus rituais mítico/religiosos, empregados para afugentar as doenças sejam elas 
do corpo ou do espírito.

Falar em medicina tradicional no Brasil equivale a dizer do intercâmbio de costumes e conhecimentos sobre tratamentos de doenças relacionados ao uso de plantas medicinais e outros elementos, que teve início com o processo de colonização empreendido pelos europeus a partir do século XVI. Deste processo participaram todos os povos responsáveis atualmente pela rica diversidade cultural e étnica característica do país, pelo amálgama de conhecimentos específicos e pela formação do sincretismo religioso presentes nas diversas regiões do país, principalmente nas zonas rurais. Segundo Ribeiro: "Para os autores folcloristas, a medicina rústica brasileira seria uma sobrevivência das artes de curar indígena, negra e ibérica [...] (1987, p. 136)".

Nesse contexto, as mulheres sempre tiveram (e ainda têm) importante papel, pois, geralmente, estão ligadas às funções relacionadas à fertilidade, à alimentação da família e aos cuidados com os idosos, com as crianças, inclusive os recém-nascidos; isto é, a mulher também é cuidadora. Muitas mulheres avançaram nessas funções e responsabilidades. tornando-se detentoras de conhecimentos fitoterápicos, de obstetrícia e, ainda, de práticas espiritualistas, tais como a de rezar e benzer doentes. Dito de outro modo, a mulher sempre ocupou e ocupa importante papel na medicina tradicional. Conforme a historiadora francesa Michele Perrot (2005, p. 218-219),

\footnotetext{
Antes de serem as auxiliares reverentes, ansiosas e sempre oculpadas pelos médicos, as mulheres do povo foram, ao contrário, suas principais rivais e as continuadoras de uma medicina popular cujas virtudes se tende a reavaliar nos dias de hoje. Elas usam todos os recursos de um farmacopéia multissecular, conhecem cem maneiras de aliviar pequenas dores cotidianas que deixam tantas vezes a medicina erudita desarmada. Analisando de perto esses "remédios de mulher" revelariam provavelmente um real saber sobre o sofrimento do povo, preocupado em evitar despesas, mas também em conservar a autonomia corporal e subtrair-se ao olhar do médico, este olhar que ausculta, mede, classifica, elimina e, para terminar, envia a pessoa ao hospital maldito.
}

As mulheres que iniciaram a prática da medicina tradicional no Brasil tiveram como base os conhecimentos recebidos dos povos indígenas, dos negros africanos e, também, aqueles herdados do mundo medieval e que se constituem pelo uso de plantas com poder curativo, de rituais religiosos de cura, de simpatias, de benzeções que remetem aos rituais das bruxas perseguidas pela Inquisição, e que foram introduzidos aqui pelos portugueses.

Em seu texto sobre a magia e a medicina na Colônia, a historiadora Mary Del Priore (1997) nos apresenta diversos episódiossobre a medicina popular ou tradicional. Para a autora, no Brasil Colônia, aqueles ou aquelas que a praticavam recebiam a alcunha de 
parteiras, benzedeiras ecurandeiras, e atuavam tanto na zona rural quanto nos grandes centros, e, mesmo perseguidas pelas autoridades civis e religiosas, exerciam seu ofício com desembaraço, usando de terapêutica clássica, popular, mágica ou sugestiva, e contavam com a estima e o respeito do povo pobre. Mais do que os homens, as mulheres eram as que mais necessitavam dos recursos da medicina para o alívio dos incômodos provenientes da menstruação, da gravidez, do parto, da menopausa etc. Porém, sem acesso à medicina oficial e partindo da concepção que alegava que a doença seria fruto de uma ação sobrenatural e, ainda, de uma visão mágica do corpo, as mulheres daquele tempo acumulavam um saber sobre o uso de plantas, minerais e animais na fabricação de remédios para combater as doenças cotidianas.

Na Colônia, o conhecimento acumulado pela medicina tradicional é uma herança de indígenas e africanos, mas também de europeus. Nesse sentido, é emblemático o trecho recortado da pesquisa de Priore (1997, p. 94):

\begin{abstract}
Uma planta chamada 'malícia de mulher' [...] que fechava a corola quando tocada, foi muito usada para problemas uterinos. O goembeguaçu era uma erva que muito servia aos fluxos de mulheres. [...] Outro documento setecentista também evidencia a dimensão dessa botica achada facilmente na horta, típica do saberfazer das curandeiras e benzedeiras: a manjerona metida na natura provoca o mênstruo e enxuga corrimentos. A murta mostrava-se eficiente para conter fortes hemorragias e o nardo mencionado na operação mágica contra quebranto servia também para combater inflamações. [...] Um processo de inquisição contra Natália Josefa, benzedeira portuguesa, revela como era feita a manipulação desta flora, com a finalidade de "se apertar hua mulher".
\end{abstract}

Desse modo, as mulheres, em busca de cura para suas próprias doenças e para seu grupo familiar, acumulavam saberes transmitidos oralmente, fruto de uma junção de culturas, cuja origem era proveniente do mundo vegetal. Havia a crença de que certas plantas serviam tanto aos males do corpo quanto do espírito e, muitas vezes, essas plantas serviam a finalidades diferentes. Segundo Priore (1997), o cheiro do alecrim servia como antídoto contra os raios; seus ramos tinham poder contra feitiços.

A cura ou outro efeito das plantas não se localizava somente em suas propriedades, mas no ritual, na magia. Por isso, as ervas colhidas na quinta feira de ascensão tinham virtudes contra sezões, febres e bruxedos. $\mathrm{O}$ ato de queimar folhas de figueira em casa onde havia criança pequena secava o leite da mãe. Já o funcho, o rosmaninho, o sabugueiro e o alecrim colhidos na manhã de São João livravam a casa de enfermidades. Da arruda colhida em dia de Natal à meia noite, devia fazer-se chá, para ser tomado no caso de haver alguma doença.

Muitas dentre estas plantas, ainda hoje comuns entre nós, não são de origem 
brasileira e foram introduzidas pelos portugueses;como exemplo, temos o alecrim, o sabugueiro e o funcho. Outras tantas, de acordo com Ribeiro (1987), também passaram a fazer parte da medicina tradicional, mesclando as culturas ibérica, indígena e africana, tais como o cravo da índia, o hortelã, o poejo,aalfavaca,d o sândalo; a canela dentre outras. A autora nos alerta para o fato de que "[...] algumas destas espécies, como o cravo e a canela ... tem similares nativos.” (RIBEIRO, 1987, p. 50).

Nesse contexto, os jesuítas, conforme observa Karash (2000),tiveram um papel significativo, uma vez que foram eles os responsáveis por introduzirem, na colônia, estas plantas com propriedades medicinais de origem européia, bem como por difundirem o seu uso.

Segundo Ribeiro (1997), os contornos das artes de curar no Brasil se deram pelas contribuições das populações formadoras da sociedade brasileira, os indígenas, os africanos e os europeus. A historiadora Laura de Mello e Souza (1987), por sua vez, afirma que os índios e mestiços ocuparam lugares de destaque nas funções terapêuticas no Brasil.

Em sua obra Medicina Rústica, Alceu Maynard Araújo (1979) descreve a pajelança indígena e o candomblé afro-brasileiro como práticas da medicina, mas identifica nessas práticas aspectos inerentes à magia e à religião. Para ilustrar a relação entre a medicina e a mágia, o autor nos lembra da benzedura, dasimpatia, da profilaxia mágica, dotoré, da advinhação, dadefumação e do uso de ervas. As raízes da medicina religiosa podem ser identificadas no catolicismo popular e no candomblé, naadivinhação simbólica, na homenagem a algumadivindade, no reparo de alguma "ofensa" a ela causada e mesmo na terapêutica do próprio rito. Entretanto, consideramos que é o sincretismo que caracteriza a religiosidade brasileira, pois estas práticas não podem ser separadas de maneira estanque, muitas delas aparecem tanto em uma como em outra vertente. Isto é, tanto no terreno da medicina mágica quanto da religiosa, o uso da fitoterapia, dos rituais e das benzeduras se fundem.

Todavia, é nos chamados males da madre que se situam as questões relacionadas à sexualidade da mulher e se constitui o maior desafio tanto para os médicos quanto para as próprias mulheres. Afrânio Peixoto,em sua obra Miçangas (1977, 45), publicada pela primeira vez em 1931, explica que madre - mãe do corpo - é o útero, uma vez que: “Os sertanejos supõem que a madre do corpo é sujeita a errar por ele, produzindo desordens variadas. Talvez seja o empirismo primitivo que deu mesmo à ciência a noção de histeria (histeros, útero) nevrose proteiforme que se ligava a doenças uterinas".

Com o objetivo de desvendar esse universo no Brasil Colônia, Priore (1993) 
recorre ao Erário Mineral de Luís Gomes Ferreira, cujos dados dizem respeito à classificação das doenças setecentista e à rapidez da contaminação das mulheres por meio das relações sexuais, ressaltando as chagas genitais que decorrem de tais enfermidades. Essa obra nosológica expressa as realidades do campo da ciência. Contudo, permaneciam na mentalidade das mulheres os hábitos de se tratar com purificações e encantamentos, respaldando o saber metafísico e uma concepção mágica do corpo e da doença. Tal mentalidade era, muitas vezes, incorporada e reelaborada pela medicina, evidentemente representada por homens, outras vezes pela própria Igreja, que se inspirava nessas práticas populares para produzir um discurso espiritual e piedoso.

O funcionamento natural da madre representava para as mulheres da Colônia os ritimos de seu ciclo vital. As regras marcavam o momento da fecundidade que resultava na maternidade, e em seguida, da monapausa, registrando o fim da possibilidade de procriação. A pesquisa de Priore (1993) identifica diversos rituais de feitiçaria que envolviam o sangue menstrual, o qual era considerado base da magia de transformações femininas, como o azedamento dos vinhos, leite e manteiga.

Peixoto (1977)menciona a crença popular de que a mulher que pisa em cobra, estando menstruada, faz com que o animal "inteiriça-se e morra" (1977, p. 25). Em outra passagem, este autor faz referência às práticas populares para a cura do terço, nome popular dado à conjuntivite, dentre as quais destacamos a seguinte: o terçol [...] "trata-se esfregando o olho com a barra da saia de uma mulher menstruada[...]" (1977, p.36).

Quanto aos médicos, estes consideravam que a fonte das doenças era a madre, dela decorriam todas as demais enfermidades, pois o útero simbolizava um terreno remanescente, podendo adoecer, mas também fechar o corpo da mulher. "Curar significava sempre dar a esse corpo um estado natural de vacuidade que só poderia ser substituído pela gravidez; daí a obsessão por sangrias, vomitórios, lavagens, purgantes e sudoríferos, tudo enfim que ajudasse a liberar o organismo doente". (PRIORE, 1993, p. 221)

Ainda de acordo com Priore (1993), um manuscrito na Colônia recomendava desde chifre de veado em pó para a madre saída do lugar a avenca cozida, sob a forma de emplasto, junto com o uso da própria urina da doente, tomada por via oral. Assim, as mulheres com suas doenças sobreviviam por meio de saberes transmitidos oralmente, utilizando-se dos vegetais cultivados no quintal, local onde se colhiam as ervas para as curas, mas onde também se jogavam as águas usadas na lavagem das roupas sujas de menstruação, as mesmas que lavavam os mortos e os recém-nascidos. Portanto, o quintal constituía-se espaço privilegiado da economia familiar e expressava o prestígio da cultura feminina, feita 
de um conhecimento empírico, oral, guardado na memória visual que no Antigo Regime começa a ser apropriado pelos médicos e transformado em conhecimento científico.

Contudo, no Brasil, foi preciso muito tempo para que os médicos se envolvessem com a obstetrícia. Tal recusa era justificada pelos profissionais da medicina devido ao próprio desconhecimento em relação a dor e a anatomia feminina, ignorando onde cortar e como suturar e estancar hemorragias e infecções, portanto

[...] entre o pudor e a imperícia, as mulheres e seus problemas de saúde foram relegados a um espaço próprio, no qual os médicos custaram a se envolver. As parteiras aprendiam pela prática, provavelmente no contato com outras parteiras mais velhas, que guardavam conhecimentos do funcionamento do corpo feminino que não eram comuns. As parteiras compartilhavam da vida das mulheres que tratavam, resolvendo seus 'incômodos', guardando seus segredos e mantendo suas amizades. Eram mulheres que exerciam os mesmos papéis cotidianos que as demais, mas também podiam dar socorro no caso de alguma doença e, principalmente, ajudavam as mulheres a 'dar à luz'. Tinham um profunda inserção no quotidiano do espaço doméstico, incluindo as crianças, os vizinhos, os parentes, num universo governado pelos valores femininos (WEBER, 2004, p. 178).

Desse modo, os "incômodos do útero" tratados pelas parteiras poderiam abarcar desde doenças venéreas até abortos. Os tratamentos empregados constituíam-se "[...] lavagens de água fervida e líquidos "perfumosos", tampões de tecido introduzidos no útero (curativos), "sublimados corrosivos" etc.” (WEBER, 2004, p. 179).

\section{Considerações finais}

O presente artigo começa com uma reflexãosobre as doenças e as lutas sociais que assolaram a Europa feudal no período de transição para a modernidade, seguindo com a ideia de que a caça às bruxas foi um dos mais importantes acontecimentos do desenvolvimento da sociedade capitalista e da formação do proletariado moderno. Conforme extensa pesquisa de Federici (2017), a perseguição e o terror desencadeados contra as mulheres nesse período debilitou a capacidade de resistência do campensinato europeu frente ao ataque lançado pela aristocracia latifundiária e pelo Estado. Essa política de devastação que visava a desintegração do campensianto não se deu de forma isolada, e sim combinada com a privatização da terra, com o aumento dos impostos e do controle estatal sobre todos os aspectos da vida social.

Além disso, a caça às bruxas aprofundou a divisão entre mulheres e homens, levando os homens a temer o poder das mulheres, e também destruiu um conjunto de práticase conhecimentos, especialmente relacionadas à cura de doenças, como a sexualidade 
e contracepção, dentre outras, cuja existência era incompatível com a disciplina do trabalho capitalista.

No Brasil, de acordo com Priore (1997), doença e culpa se misturavam, o corpo feminino era visto tanto por pregadores da Igreja quanto por médicos como um espaço obscuro onde Deus e o diabo se degladiavam. Em geral, considerava-se que as doenças que atingiam as mulheres provinham de feitiços e, por isso, eram um sinal demoníaco. Restava, portanto, às próprias mulheres no papel de curandeiras ou benzedeirasretirar a doente do mundo profano, por meio de palavras, prescrições e objetos simbólicos.

No mundo medieval, como no Brasil colônia, as atividades de cura e tratamento foram responsabilidades quase exclusivas das mulheres. Além de cuidadoras de crianças, de velhos e de doentesem geral, funções consideradas femininas por diversas sociedades, algumas delas foram além e tornaram-se guardadoras, difusoras e reprodutoras de inúmeros conhecimentos, teóricos e práticos da medicina rústica, tanto seculares, quanto de cunho mítico.

As mulheres dominavam o conhecimento das diversas plantas nativas e estrangeiras, introduzidas no país pelos europeus. Conheciam as suas principais características, isto é, formas de cultivo, de preparo e as suas especificidades curativas. Elas conheciam, também, os segredos da cura mítica e, por meio de um sincretismo religioso, cujas práticas mesclavam catolicismo popular, toré,candomblé e outros, lançando mão de rezas, benzeções, rituais e simpatias a quem solicitasse seus serviços, que, por sinal, não eram remunerados.

Embora o uso do verbo no passado nos parágrafos acima, é importante refletir sobre o fato de que a medicina rústica ainda está presente no Brasil, principalmente nas regiões menos privilegiadas economicamente, entretanto, não exclusivamente. Nos grandes centros urbanos, existem ainda os vendedores de ervas e raízes, os fazedores de garrafadas, as rezadoras e as benzedeiras. Trata-se de uma característica cultural da nossa trajetória histórica que pode ser identificada na temporalidade da longuíssima duração, como define F. Braudel, (2007). Outrossim, é importante enfatizar que, neste contexto, as ações femininas ainda se fazem muito presentes.

\section{Referências}

ARAÚJO, Alceu Maynard. Medicina Rústica. São Paulo: Editora Nacional, 1979.

AUGIER, Marie. Du créditpublic [Do Crédito Público]. EditoraFarmington Hills, Mich: 
Thomson Gale, 2005.

BRAUDEL, Fernand. História e Ciências Sociais: a longa duração. In: Escritos sobre a História. Trad. J. Guinburg e Tereza Cristina Silveira da Mota. São Paulo: Perspectiva, 2007

CASTEL, Robert. As metamorfoses da questão social: uma crônica do salário.Petrópolis: $2^{a}$ Edição, Vozes, 1999

CORBIN, A. Bastidores. In: ARRIES e DUBY. História da vida privada. São Paulo: Companhia das Letras, 1991. v. 4.

KARASH, M. C. A vida dos escravos no Rio de Janeiro (1808-1850). São Paulo: Editora Schwarcz Ltda., 2000.

KURZ, Robert. Escorrendo sangue e sujeira por todos os poros: o vilão capitalismo e sua barbárie (2001). Disponível em: 〈http://www.obeco-online.org/rkurz427.htm> Acesso em: 14/07/2020.

MURARO, Rose Marie. Introdução. In: KRAMER, Heinrich e SPRENGER, James. O martelo das feiticeiras. Trad. de Paulo Fróes. Rio de Janeiro: BestBolso, 2015.

MARX, Karl.O Capital: Crítica da economia política. Livro I: O processo de produção do capital. Trad. Rubens Enderle. São Paulo: Boitempo, 2013.

PEIXOTO, Afrânio. Miçangas. Rio de Janeiro: Catédra, 1977.

PERROT, Michele. As mulheres e os silêncios da história. Bauru: EDUSC, 2005.

PRIORE, Mary Del. Magia e medicina na Colônia: o corpo feminino. In: PRIORE, Mary Del. História das Mulheres no Brasil. São Paulo: 2a . Ed. Contexto, 1997.

PRIORE, Mary Del. Ao sul do corpo: Condição feminina, maternidades e mentalidades no Brasil Colônia. Rio de Janeiro/RJ: Editora José Olympio, 1993.

REZENDE, JM. À sombra do plátano: crônicas de história da medicina [online]. São Paulo: Editora Unifesp, 2009. As grandes epidemias da história. pp. 73-82. ISBN 978-85-6167363-5. Disponível em: http://books.scielo.org/. Acesso em 15/04/2020.

RIBEIRO, Berta G. O índio na cultura brasileira. Rio de Janeiro: UNIBRADE/UNESCO, 1987.

RIBEIRO, Márcia Moisés. A Ciência nos Trópicos: A arte médica no Brasil do século XVIII. São Paulo, SP: Hucitec, 1997.

SOUZA, Laura de Mello e. O diabo e a Terra de Santa Cruz. São Paulo: Companhia das Letras, 1987.

WEBER, Beatriz Teixeira. Fragmentos de um Mundo Oculto: práticas de cura no sul do Brasil. In: HOCHMAN, Gilberto (org). Cuidar, controlar, curar - ensaios histórico sobre saúde e doença na América Latina e Caribe. Rio de Janeiro: FIOCRUZ, 2004, p. 157-215. 
WONG, J. Carreiras em Medicina Complementar e Alternativa: Um Panorama Geral. Universia Science. Disponível em: http://www.universia.com.br/nextwave /ver_materia.jsp?materia=100\&subcanal=13. Acesso em: 22/12/2019

Recebido em 20/08/2020

Aprovado em 10/10/2020

Publicado: $1^{\circ} / 01 / 2021$

iDoutora em Políticas Públicas pela Universidade Federal do Rio de Janeiro, mestre em História pela Universidade Federal de Goiás; docente na graduação do curso de História e no Programa de Pós Graduação Strictu Sensu Interdisciplinar: Territórios e Expressões Culturais do Cerrado - TECCER - Universidade Estadual de Goiás - UEG

ii Doutora em Educação pela Unicamp/SP, docente na graduação naUnidade de Ciências Socioeconômicas e Humanas de Anápolis e no Programa de Pós Graduação Interdisciplinar em Educação, Linguagem e Tecnologias - PPG/IELT - Universidade Estadual de Goiás - UEG 